Review article

\title{
Clinical and biochemical footprints of inherited metabolic diseases. II. Metabolic liver diseases
}

\author{
Carlos R. Ferreira ${ }^{\mathrm{a}, *}$, David Cassiman ${ }^{\mathrm{b}, *}$, Nenad Blau ${ }^{\mathrm{c}, \mathrm{d}, *}$ \\ ${ }^{a}$ National Human Genome Research Institute, National Institutes of Health, Bethesda, MD, USA \\ ${ }^{\mathrm{b}}$ Department of Gastroenterology-Hepatology and Metabolic Center, University of Leuven, Leuven, Belgium \\ ${ }^{\mathrm{c}}$ Dietmar-Hopp Metabolic Center, University Children's Hospital, Heidelberg, Germany \\ ${ }^{\mathrm{d}}$ Division of Metabolism, Children's Hospital, Zürich, Switzerland
}

\section{A R T I C L E I N F O}

\section{Keywords:}

Metabolic liver disease

Inborn errors of metabolism

Inherited metabolic diseases

Hepatomegaly

Cholestasis

Steatosis

Fatty liver

Cirrhosis

Elevated liver enzymes

Acute liver failure

Hepatocellular carcinoma

Hepatic adenomas

\begin{abstract}
A B S T R A C T
Inherited metabolic diseases account for about one third of pediatric patients with hepatomegaly, acute liver failure, cirrhosis or cholestasis. Specifically for pediatric acute liver failure, they account for 10-15\% of cases, with a mortality of $22-65 \%$. The percentage of acute liver failure caused by an inherited metabolic disease in children $<2-3$ years of age is even higher, ranging from a third to half of all cases. Metabolic liver disease accounts for $8-13 \%$ of all pediatric liver transplantations. Despite this high burden of disease, underdiagnosis remains common. We reviewed and updated the list of known metabolic etiologies associated with various types of metabolic liver involvement, and found 142 relevant inborn errors of metabolism. This represents the second of a series of articles attempting to create and maintain a comprehensive list of clinical and metabolic differential diagnoses according to system involvement.
\end{abstract}

\section{Introduction}

This is the second in a series of articles that intends to provide a comprehensive list of inherited metabolic diseases associated with specific signs and symptoms. The list will follow the classification as included in the knowledge base of inborn errors of metabolism (IEMbase) [1] and in the recently proposed Nosology of inborn errors of metabolism (IEMs) [2]. The second issue of our series will be dedicated to metabolic liver disease (MLD).

Manifestations of liver involvement caused by inherited metabolic diseases are not uncommon. As can be seen in more detail in Table 1, they represent $10-15 \%$ of all causes of acute liver failure in children $<18$ years old, with a mortality of $22-65 \%$. In children $<2-3$ years of age, the percentage of acute liver failure caused by MLD rises to $33-53 \%$. Mitochondrial depletion syndromes alone accounted for $13 \%$ of acute liver failure in children younger than 2 years old $(5 / 29)$ [3] and $22 \%$ in infants $(11 / 50)$ [4]. The percentage of pediatric liver transplantation due to MLD, on the other hand, varies from $8 \%$ [5] to $10 \%$ (310/2997, excluding cystic fibrosis and $\alpha-1$ antitrypsin deficiency) [6] to $13 \%(73 / 575$, excluding $\alpha-1$ antitrypsin deficiency and neonatal hemochromatosis) [7].

In a cohort of 493 patients seen at a specialty hospital for pediatric liver and biliary diseases, 29.6\% (146 patients, excluding one with cystic fibrosis) had a metabolic etiology [18]. Specifically, a metabolic etiology accounted for cirrhosis in $21 \%$ of cases $(54 / 260)$ and cholestasis in $28 \%$ of cases (25/89). Another cohort found that $2.5 \%(11 / 450)$ of cases of infantile cholestasis are caused by mitochondrial depletion syndromes [4].

With increased attention for IEMs in adults, increasing numbers of children with IEMs becoming adults, and increasing availability of high throughput genetic diagnostics, the expectation is that many 'cryptogenic' cirrhosis cases in adults and many hitherto unexplained adult cases of acute liver failure (ALF) will receive metabolic diagnoses. Indeed, end-stage liver disease secondary to cryptogenic cirrhosis is the indication for orthotopic liver transplantation (OLT) in $7 \%$ to $14 \%$ of recipients [19], whereas a specific etiology cannot be identified in $15 \%$ of adult ALF cases [20].

\footnotetext{
*Corresponding author at: National Human Genome Research Institute, National Institutes of Health, 10 Center Drive, MSC 1851, Building 10, Room 9N248B, Bethesda, MD 20892, USA.

E-mail addresses: ferreiracr@mail.nih.gov (C.R. Ferreira), david.cassiman@kuleuven.be (D. Cassiman), nenad.blau@med.uni-heidelberg.de (N. Blau).
} 
Table 1

Percentage of pediatric acute liver failure attributed to inherited metabolic disease.

\begin{tabular}{|c|c|c|c|c|}
\hline Age & $\begin{array}{l}\text { Metabolic liver } \\
\text { disease (MLD) }\end{array}$ & $\begin{array}{l}\text { MLD } \\
\text { mortality }\end{array}$ & Indeterminate & Ref \\
\hline$<90 \mathrm{~d}$ & $28 / 148(19 \%)$ & $29 \%$ & $56 / 148(38 \%)$ & {$[8]$} \\
\hline$<120 \mathrm{~d}$ & $28 / 78(36 \%)$ & $8 / 28(29 \%)$ & $5 / 78(6 \%)$ & [9] \\
\hline Infants $(<12 \mathrm{~m})$ & $34 / 80(43 \%)$ & $\begin{array}{l}14 / 34 \\
(41 \%)\end{array}$ & $13 / 80(16 \%)$ & [10] \\
\hline $\begin{array}{c}<24 \mathrm{~m} \text { (median } \\
1.3 \mathrm{~m} \text { ) }\end{array}$ & $18 / 34(53 \%)$ & $8 / 18(44 \%)$ & - & [11] \\
\hline$<2 \mathrm{y}$ & $12 / 28(43 \%)$ & $3 / 12(25 \%)$ & $5 / 28(18 \%)$ & [12] \\
\hline $\begin{array}{c}<3 \mathrm{y} \text { (median } \\
12.5 \mathrm{~m})\end{array}$ & $10 / 30(33 \%)$ & $7 / 10(70 \%)$ & $3 / 30(10 \%)$ & [13] \\
\hline$<18 \mathrm{y}$ & $14 / 109(13 \%)$ & $8 / 14(57 \%)$ & $16 / 109(15 \%)$ & [14] \\
\hline $0-18 y$ & $36 / 348(10 \%)$ & $8 / 36(22 \%)$ & $169 / 348(49 \%)$ & [15] \\
\hline $0-17 y$ & 15/97 (15\%) & $\begin{array}{l}11 / 17 \\
(65 \%)\end{array}$ & - & [16] \\
\hline Neonatal $(<1 \mathrm{~m})$ & $3 / 17(18 \%)^{\mathrm{a}}$ & - & & \\
\hline Infants $(1-12 \mathrm{~m})$ & $7 / 22(32 \%)$ & & & \\
\hline $\begin{array}{l}\text { Early childhood } \\
\quad(1-5 y)\end{array}$ & $3 / 33(14 \%)$ & & & \\
\hline $\begin{array}{l}\text { Late childhood } \\
\qquad(5-17 \text { y) }\end{array}$ & $2 / 36(6 \%)^{\mathrm{b}}$ & & & \\
\hline $0-18 y$ & $25 / 215(12 \%)$ & - & $68 / 215(32 \%)$ & [17] \\
\hline Neonatal $(<28 \mathrm{~d})$ & $5 / 42(12 \%)$ & & $2 / 42(5 \%)$ & \\
\hline Infants ( $29 \mathrm{~d}-1 \mathrm{y})$ & $3 / 23(13 \%)$ & & $8 / 23(35 \%)$ & \\
\hline Child (1-12 y) & $12 / 95(13 \%)$ & & $41 / 95(43 \%)$ & \\
\hline $\begin{array}{l}\text { Adolescent } \\
\quad(12-18 y)\end{array}$ & $5 / 55(9 \%)$ & & $17 / 55(31 \%)$ & \\
\hline
\end{tabular}

a Excluding neonatal hemochromatosis.

b Both Wilson disease.

\section{Signs and symptoms}

We categorized the signs and symptoms of MLD as: hepatomegaly; hepatocellular disease with either elevation of transaminases or frank acute liver failure; cholestasis; steatosis; fibrosis or cirrhosis; and liver tumors (see Supplemental Table 1, also available at www.iembase.org/ gamuts).

The definition of acute liver failure differs between adults and children and varies in different publications. In adults, acute liver failure is defined by a combination of jaundice, hepatic encephalopathy and clotting abnormalities. In contrast, encephalopathy is not required to make the diagnosis of acute liver failure in children, as it is more difficult to assess. Although no formal definition of liver failure exists in children, the entry criteria for the Pediatric Acute Liver Failure (PALF) study are commonly used, those being a hepatic-based coagulopathy with a prothrombin time (PT) $\geq 15 \mathrm{~s}$ or international normalized ratio (INR) $\geq 1.5$ not corrected by vitamin $\mathrm{K}$ in the presence of clinical hepatic encephalopathy, or a PT $\geq 20 \mathrm{~s}$ or INR $\geq 2.0$ regardless of the presence or absence of clinical hepatic encephalopathy [15]. Lack of correction by vitamin $\mathrm{K}$ is defined as persistent coagulopathy $6 \mathrm{~h}$ after a second dose of parenteral vitamin $\mathrm{K}$ [13]. The fact that the coagulopathy has a hepatic etiology requires biochemical evidence of liver injury, generally as elevated aspartate aminotransferase (AST), alanine aminotransferase (ALT), and/or total and conjugated bilirubin [21]. Acute or fulminant is defined as onset of liver failure within eight weeks of onset of clinical liver disease, in a patient with no previous evidence of chronic liver disease; onset within six months is sometimes called subacute or subfulminant liver failure [21].

Supplemental Table 1 summarizes in detail IEMs, including diagnostic markers, associated with liver involvement. Hepatocellular disease was included as either acute liver failure, or as elevation of transaminases in cases where a formal definition of acute liver failure is not always appropriate (such as in cases with previous evidence of chronic liver disease, or with onset of liver failure beyond eight weeks of onset of liver disease). Where 'steatosis' is mentioned, this can be radiological or pathological steatosis.

\section{Diagnosis and differential diagnosis}

It is likely that metabolic etiologies of acute liver failure remain underdiagnosed. In a cohort of 329 patients with indeterminate pediatric acute liver failure, 179 (54\%) had no testing for common metabolic disorders [22]. Depending on age, $55.9-87.5 \%$ and $33.8-56.9 \%$ of patients had no acylcarnitine profile or urine organic acid analysis performed, respectively. In 53 infants younger than 3 months of age, only $57 \%$ had screening for tyrosinemia, and $52 \%$ had screening for galactosemia [22].

Some clinical and laboratory features are known to increase the likelihood of MLD as compared to other diagnoses. There is a significant difference in the median jaundice-to-encephalopathy interval (60 days vs 15 days) and glycemia $(p=.001)$, with a longer interval and a higher chance of hypoglycemia in patients with MLD. Other highly discriminating parameters were a suggestive family history, with an odds ratio (OR) of 3.73, developmental delay (OR 4.4), and presence of diarrhea or vomiting (OR 3.28) The family history was considered suggestive of MLD when there was consanguinity, neonatal deaths/ sudden infant death syndrome in the family, unknown deaths in siblings, or a similar history in the family [13]. In a cohort of children younger than 2 years old with acute liver failure, failure to thrive and/ or vomiting were more frequent in patients with MLD $(p=.022)$ [12].

Red flags suggesting that liver involvement might be caused by an IEM include: 1) a suggestive family history, such as recurrent miscarriages, neonatal deaths, sudden infant death syndrome (SIDS), psychiatric illness, parental consanguinity, acute fatty liver of pregnancy or HELLP syndrome; 2) recurrent presentation during episodes of catabolism, such as febrile illness or prolonged fasting; 3) recurrent or chronic vomiting or diarrhea; 4) failure to thrive; 5) presence of dysmorphic features; 6) food aversion; 7) unusual fluid odors; and 8) evidence of systemic involvement, such as developmental delay, hypotonia, seizures, cataracts, optic atrophy or renal tubular involvement [18]. clue.

The age of onset of symptoms can also represent a helpful diagnostic

Causes of acute liver failure in young infants include galactosemia, tyrosinemia, mitochondrial depletion syndromes, congenital disorders of glycosylation, and Niemann-Pick type C. Hereditary fructose intolerance becomes more prevalent after 4-6 months of age, when fructosecontaining foods are introduced at the time of weaning from breast milk. However, it can present at any age, even in the neonatal period, as many infant formulas contain fructogenic compounds [23]. The fructose and sucrose content of commercially available infant formulas has been reviewed elsewhere [24]. Wilson disease remains the most common metabolic cause of acute liver failure in late childhood and adolescence. Mitochondrial disorders [25], fatty acid oxidation defects and urea cycle disorders can present at any age. Other IEMs can manifest by recurrent liver failure with intercurrent illness, such as longchain fatty acid oxidation defects, and dihydrolipoamide dehydrogenase (E3) deficiency [26].

Some conditions are not uniformly considered as IEMs in a strict sense, but present great phenotypic overlap. Examples include intracellular trafficking defects such as NBAS [27], and SCYL1 [28,29] deficiencies, and cytosolic tRNA synthetase deficiencies such as LARS [30,31], MARS [32], and IARS [33] deficiencies, all of which can present with infantile hepatopathy, including recurrent liver failure. Other trafficking defects, such as VPS33B and VIPAS39 deficiencies, can present with hepatopathy and proximal renal tubular involvement $[34,35]$. Some of them might even be amenable to therapy, as has been described with high-protein intake in cases of liver failure from LARS deficiency [36], or zinc supplementation in a case with IARS deficiency [33]. Phenotypic overlap exists not only with other genetic disorders, but also with non-genetic conditions. For example, neonatal hemochromatosis is most commonly caused by gestational alloimmune liver disease (GALD), where the mother produces antibodies against fetal 
Table 2

Biochemical investigations in metabolic liver diseases.

\begin{tabular}{lll}
\hline Chemistry & Profiles & Special tests \\
\hline Blood count & Amino acids (P, U) & Copper (S, U) \\
Coagulation factors $_{\text {Urinalysis }}{ }^{\text {C }}$ & Organic acids (U) & Ceruloplasmin (S) \\
Lipid panel (S) $_{\text {Ammonia (B) }}$ & Acylcarnitines (DBS, P) & LS-Enzymes (DBS) \\
Glucose (P) & Porphyrins (U, P, RBC) & Alpha-fetoprotein (S) \\
Lactate (P, CSF) & VLCFA (P) & SAH \& SAM (P) \\
Total/direct bilirubin (S) & Sialotransferrins (S) & Sulfatides (U) \\
Iron (S) & Purines (U) & Vitamins A, D, E, K (S) \\
Ferritin (S) & Bile acids (S, U) & Galactose-1-P (RBC) \\
AST/ALT (P) & Sterols (P) & \\
GGT (P) & & \\
ALP (P) & & \\
CK (P) & & \\
\hline
\end{tabular}

${ }^{\text {a }}$ Dipstick urine chemistry.

hepatocytes [37]. However, a diagnosis of deoxyguanosine kinase deficiency should be entertained in the differential diagnosis of neonatal hemochromatosis [38-40]. In fact, in a case series of 22 patients diagnosed with neonatal hemochromatosis, 1 (5\%) was found to have deoxyguanosine kinase deficiency [41].

A few laboratory diagnostic pearls are presented as follows:

1) Patients with liver failure from tyrosinemia type 1 can have normal or near normal transaminases $[9,42]$.

2) A low alkaline phosphatase to total bilirubin ratio (ALP/TB ratio) and a high AST/ALT ratio (De Ritis ratio) in the setting of acute liver failure point to Wilson disease as the underlying etiology. An ALP/ TB ratio $<4$ had a sensitivity of $94 \%$, specificity of $96 \%$, and likelihood ratio of 23, while an AST/ALT ratio > 2.2 had a sensitivity of $94 \%$, specificity of $86 \%$, and likelihood ratio of 7 for diagnosing fulminant Wilson disease. Combining both ratios had a diagnostic sensitivity and specificity of $100 \%$ [43]. Sometimes even more stringent ratio cutoffs are used, with an ALP/TB ratio $<2$ and AST/ALT ratio $>4.0$ [44]. A combination of acute liver failure with Coombs negative hemolysis (partly responsible for the skewed ALP/TB ratio) and/or tubulopathy (glucosuria, amino-aciduria, phosphaturia) also points to Wilson.

3) Normal complex II (encoded exclusively by nuclear genes) activity in combination with reduced complex I, III and IV activities should raise suspicion for mitochondrial depletion syndrome [45].

4) The preferred screening method for mitochondrial depletion syndrome is by DNA sequencing, as liver mitochondrial DNA content analysis can reveal secondarily low mitochondrial DNA copy number in the setting of acute liver failure from other etiologies [3].

5) A normal $\gamma$-glutamyl transferase GGT in the setting of cholestasis indicates a disorder of bile acid synthesis, bile acid transport, or intracellular trafficking. GGT is located in the luminal side of the plasma membrane of bile duct epithelial cells. In most cases of cholestasis, the increased availability of bile acids in the lumen of the bile ducts will facilitate the detachment of the GGT from the canalicular membrane. Thus, disorders of bile acid synthesis [46] and of bile acid transport (ATP8B1 and ABCB11 deficiencies) [47] are associated with a low or normal GGT. Similarly, disorders of intracellular trafficking such as SCYL1 deficiency [29], ARC syndrome [34] due to VPS33B or VIPAS39 deficiencies, and MYO5B deficiency $[48,49]$ can also be associated with cholestasis with normal GGT, likely due to mislocalization of a bile acid transporter $[49,50]$.

The interval between presentation of acute liver failure and the need to decide whether or not to transplant is still too short to allow extensive genetic testing, although requests for sequencing panels, whole exome sequencing, and even whole genome sequencing are becoming more frequent. The advent of broader availability and better reliability of high-throughput genetic diagnostic options will no doubt revolutionize the field, expanding the phenotypic and biochemical spectrum of the involved disease entities, identifying genetic causes in the high percentage of unsolved acute and chronic, pediatric and adult liver disease patients. Nevertheless, the need for clinical and biochemical corroboration or confirmation of the identified genetic variants will remain.

A list of laboratory investigations to aid in the diagnosis of the various listed IEM is summarized in Table 2. For more details see Supplemental Table 1. The diagnostic approach, as with all IEMs, should focus on treatable disorders.

\section{Treatment}

Some IEMs can be cured by a liver transplantation, while for others, significant metabolic impairment will persist after transplantation (reviewed in detail in [51]). For the latter group, in particular, the benefits and drawbacks of this treatment approach should be evaluated on an individual basis. Recently, the traditional exclusion of patients mitochondrial disease from liver transplantation is being reassessed [52]. With this caveat, the reported patient survival at 5 years varies from $88.9-92 \%$, and the graft survival at 5 years is $83.8 \%$ for cases of pediatric liver transplantation due to IEMs [53]. In fact, children with IEMs who receive a liver transplant are less likely to experience gastrointestinal complications, portal vein thrombosis, and surgical re-intervention within 30 days post-transplant, with an excellent patient survival and better graft survival than those who were transplanted for other indications [6]. In the case of Wilson disease, a scoring system exists based on serum bilirubin, AST, INR, WBC and albumin at presentation, with a cutoff score of 11 points as an indication for liver transplantation [54].

Supplemental Table 1 includes information on primary treatment options for the mentioned IEMs, i.e., treatment that addresses at least one aspect of the pathophysiology of the disease, when available.

\section{Conclusion}

We provide a comprehensive list of metabolic diseases associated with liver involvement, as well as a proposed battery of standard laboratory and biochemical tests to aid in diagnosis based on the many possible IEMs in the aforementioned list. This represents the second issue in a series of educational summaries providing a comprehensive and updated list of metabolic differential diagnosis according to system involvement. The full list can be accessed for free at www.iembase.org/ gamuts, and will be curated and updated on a regular basis.

Supplementary data to this article can be found online at https:// doi.org/10.1016/j.ymgme.2019.04.002.

\section{Declarations of interest}

None.

\section{References}

[1] J.J.Y. Lee, W.W. Wasserman, G.F. Hoffmann, C.D.M. van Karnebeek, N. Blau, Knowledge base and mini-expert platform for the diagnosis of inborn errors of metabolism, Genet. Med. Off. J. Am. Coll. Med. Genet. 20 (2018) 151-158.

[2] C.R. Ferreira, C.D.M. van Karnebeek, J. Vockley, N. Blau, A proposed nosology of inborn errors of metabolism, Genet. Med. Off. J. Am. Coll. Med. Genet. 21 (2019) $102-106$.

[3] P. McKiernan, S. Ball, S. Santra, K. Foster, C. Fratter, J. Poulton, K. Craig, R. McFarland, S. Rahman, I. Hargreaves, G. Gupte, K. Sharif, R.W. Taylor, Incidence of primary mitochondrial disease in children younger than 2 years presenting with acute liver failure, J. Pediatr. Gastroenterol. Nutr. 63 (2016) 592-597, https://doi. org/10.1097/MPG.0000000000001345.

[4] A. Al-Hussaini, E. Faqeih, A.W. El-Hattab, M. Alfadhel, A. Asery, B. Alsaleem, 
E. Bakhsh, A. Ali, A. Alasmari, K. Lone, A. Nahari, W. Eyaid, M. Al Balwi, K. Craig, A. Butterworth, L. He, R.W. Taylor, Clinical and molecular characteristics of mitochondrial DNA depletion syndrome associated with neonatal cholestasis and liver failure, J. Pediatr. 164 (2014), https://doi.org/10.1016/j.jpeds.2013.10.082 553559.e1-2.

[5] R.S. Venick, D.G. Farmer, J.R. Soto, J. Vargas, H. Yersiz, F.M. Kaldas, V.G. Agopian, J.R. Hiatt, S.V. McDiarmid, R.W. Busuttil, One thousand pediatric liver transplants during thirty years: lessons learned, J. Am. Coll. Surg. 226 (2018) 355-366, https:// doi.org/10.1016/j.jamcollsurg.2017.12.042.

[6] R. Arnon, N. Kerkar, M.K. Davis, R. Anand, W. Yin, R.P. González-Peralta, SPLIT Research Group, Liver transplantation in children with metabolic diseases: the studies of pediatric liver transplantation experience, Pediatr. Transplant. 14 (2010) 796-805, https://doi.org/10.1111/j.1399-3046.2010.01339.x.

[7] Y.K. Sze, A. Dhawan, R.M. Taylor, S. Bansal, G. Mieli-Vergani, M. Rela, N. Heaton, Pediatric liver transplantation for metabolic liver disease: experience at King's College Hospital, Transplantation 87 (2009) 87-93, https://doi.org/10.1097/TP. 0b013e31818bc0c4.

[8] S.S. Sundaram, E.M. Alonso, M.R. Narkewicz, S. Zhang, R.H. Squires, Pediatric Acute Liver Failure Study Group, Characterization and outcomes of young infants with acute liver failure, J. Pediatr. 159 (2011), https://doi.org/10.1016/j.jpeds. 2011.04.016 813-818.e1.

[9] R. Bitar, R. Thwaites, S. Davison, S. Rajwal, P. McClean, Liver failure in early in fancy: aetiology, presentation, and outcome, J. Pediatr. Gastroenterol. Nutr. 64 (2017) 70-75, https://doi.org/10.1097/MPG.0000000000001202.

[10] P. Durand, D. Debray, R. Mandel, C. Baujard, S. Branchereau, F. Gauthier, E. Jacquemin, D. Devictor, Acute liver failure in infancy: a 14-year experience of a pediatric liver transplantation center, J. Pediatr. 139 (2001) 871-876, https://doi. org/10.1067/mpd.2001.119989.

[11] F. Dias Costa, R. Moinho, S. Ferreira, P. Garcia, L. Diogo, I. Gonçalves, C. Pinto, Acute liver failure related to inherited metabolic diseases in young children, An. Pediatr. Barc. Spain 88 (2018) (2003) 69-74, https://doi.org/10.1016/j.anpedi. 2017.02.012.

[12] A. Brett, C. Pinto, L. Carvalho, P. Garcia, L. Diogo, I. Gonçalves, Acute liver failure in under two year-olds-are there markers of metabolic disease on admission? Ann. Hepatol. 12 (2013) 791-796.

[13] S. Alam, B.B. Lal, R. Khanna, V. Sood, D. Rawat, Acute liver failure in infants and young children in a specialized pediatric liver centre in India, Indian J. Pediatr. 82 (2015) 879-883, https://doi.org/10.1007/s12098-014-1638-6.

[14] S. Alam, R. Khanna, V. Sood, B.B. Lal, D. Rawat, Profile and outcome of first 109 cases of paediatric acute liver failure at a specialized paediatric liver unit in India, Liver Int. Off. J. Int. Assoc. Study Liver. 37 (2017) 1508-1514, https://doi.org/10. 1111/liv.13370.

[15] R.H. Squires, B.L. Shneider, J. Bucuvalas, E. Alonso, R.J. Sokol, M.R. Narkewicz, A. Dhawan, P. Rosenthal, N. Rodriguez-Baez, K.F. Murray, S. Horslen, M.G. Martin, M.J. Lopez, H. Soriano, B.M. McGuire, M.M. Jonas, N. Yazigi, R.W. Shepherd, K. Schwarz, S. Lobritto, D.W. Thomas, J.E. Lavine, S. Karpen, V. Ng, D. Kelly, N. Simonds, L.S. Hynan, Acute liver failure in children: the first 348 patients in the pediatric acute liver failure study group, J. Pediatr. 148 (2006) 652-658, https:// doi.org/10.1016/j.jpeds.2005.12.051.

[16] W.S. Lee, P. McKiernan, D.A. Kelly, Etiology, outcome and prognostic indicators of childhood fulminant hepatic failure in the United Kingdom, J. Pediatr. Gastroenterol. Nutr. 40 (2005) 575-581.

[17] N.P. Shanmugam, S. Bansal, A. Greenough, A. Verma, A. Dhawan, Neonatal liver failure: aetiologies and management-state of the art, Eur. J. Pediatr. 170 (2011) 573-581, https://doi.org/10.1007/s00431-010-1309-1.

[18] S. Alam, V. Sood, Metabolic liver disease: when to suspect and how to diagnose? Indian J. Pediatr. 83 (2016) 1321-1333, https://doi.org/10.1007/s12098-0162097-z.

[19] M.R. Charlton, M. Kondo, S.K. Roberts, J.L. Steers, R.A. Krom, R.H. Wiesner, Liver transplantation for cryptogenic cirrhosis, Liver Transpl. Surg. Off. Publ. Am. Assoc. Study Liver Dis. Int. Liver Transplant. Soc. 3 (1997) 359-364.

[20] W.M. Lee, R.H. Squires, S.L. Nyberg, E. Doo, J.H. Hoofnagle, Acute liver failure: summary of a workshop, Hepatol. Baltim. Md. 47 (2008) 1401-1415, https://doi. org/10.1002/hep. 22177 .

[21] R.H. Squires, Acute liver failure in children: etiology and evaluation, in: E.B. Rand (Ed.), UpToDate, UpToDate Inc., Waltham, MA, n.d. http://www.uptodate.com (accessed December 6, 2018).

[22] M.R. Narkewicz, D. Dell Olio, S.J. Karpen, K.F. Murray, K. Schwarz, N. Yazigi, S. Zhang, S.H. Belle, R.H. Squires, Pediatric Acute Liver Failure Study Group, Pattern of diagnostic evaluation for the causes of pediatric acute liver failure: an opportunity for quality improvement, J. Pediatr. 155 (2009), https://doi.org/10. 1016/j.jpeds.2009.06.005 801-806.e1.

[23] H. Li, H.M. Byers, A. Diaz-Kuan, M.B. Vos, P.L. Hall, S. Tortorelli, R. Singh, M.B. Wallenstein, M. Allain, D.P. Dimmock, R.M. Farrell, S. McCandless, M.J. Gambello, Acute liver failure in neonates with undiagnosed hereditary fructose intolerance due to exposure from widely available infant formulas, Mol. Genet. Metab. 123 (2018) 428-432, https://doi.org/10.1016/j.ymgme.2018.02.016.

[24] R.W. Walker, M.I. Goran, Laboratory determined sugar content and composition of commercial infant formulas, baby foods and common grocery items targeted to children, Nutrients 7 (2015) 5850-5867, https://doi.org/10.3390/nu7075254.

[25] V. Cormier-Daire, D. Chretien, P. Rustin, A. Rötig, C. Dubuisson, E. Jacquemin, M. Hadchouel, O. Bernard, A. Munnich, Neonatal and delayed-onset liver involvement in disorders of oxidative phosphorylation, J. Pediatr. 130 (1997) 817-822.

[26] A. Brassier, C. Ottolenghi, A. Boutron, A.-M. Bertrand, S. Valmary-Degano, J.P. Cervoni, D. Chrétien, J.-B. Arnoux, L. Hubert, D. Rabier, F. Lacaille, Y. de Keyzer,
V. Di Martino, P. de Lonlay, Dihydrolipoamide dehydrogenase deficiency: a still overlooked cause of recurrent acute liver failure and Reye-like syndrome, Mol. Genet. Metab. 109 (2013) 28-32, https://doi.org/10.1016/j.ymgme.2013.01.017.

[27] C. Staufner, T.B. Haack, M.G. Köpke, B.K. Straub, S. Kölker, C. Thiel, P. Freisinger, I. Baric, P.J. McKiernan, N. Dikow, I. Harting, F. Beisse, P. Burgard, U. Kotzaeridou, D. Lenz, J. Kühr, U. Himbert, R.W. Taylor, F. Distelmaier, J. Vockley, L. GhaloulGonzalez, J.A. Ozolek, J. Zschocke, A. Kuster, A. Dick, A.M. Das, T. Wieland, C. Terrile, T.M. Strom, T. Meitinger, H. Prokisch, G.F. Hoffmann, Recurrent acute liver failure due to NBAS deficiency: phenotypic spectrum, disease mechanisms, and therapeutic concepts, J. Inherit. Metab. Dis. 39 (2016) 3-16, https://doi.org/ 10.1007/s10545-015-9896-7.

[28] W.M. Schmidt, S.L. Rutledge, R. Schüle, B. Mayerhofer, S. Züchner, E. Boltshauser, R.E. Bittner, Disruptive SCYL1 mutations underlie a syndrome characterized by recurrent episodes of liver failure, peripheral neuropathy, cerebellar atrophy, and Ataxia, Am. J. Hum. Genet. 97 (2015) 855-861, https://doi.org/10.1016/j.ajhg. 2015.10.011.

[29] D. Lenz, P. McClean, A. Kansu, P.E. Bonnen, G. Ranucci, C. Thiel, B.K. Straub, I. Harting, B. Alhaddad, B. Dimitrov, U. Kotzaeridou, D. Wenning, R. Iorio, R.W. Himes, Z. Kuloğlu, E.L. Blakely, R.W. Taylor, T. Meitinger, S. Kölker, H. Prokisch, G.F. Hoffmann, T.B. Haack, C. Staufner, SCYL1 variants cause a syndrome with low $\gamma$-glutamyl-transferase cholestasis, acute liver failure, and neurodegeneration (CALFAN), Genet. Med. Off. J. Am. Coll. Med. Genet. 20 (2018) 1255-1265, https://doi.org/10.1038/gim.2017.260.

[30] J.P. Casey, P. McGettigan, N. Lynam-Lennon, M. McDermott, R. Regan, J. Conroy, B. Bourke, J. O'Sullivan, E. Crushell, S. Lynch, S. Ennis, Identification of a mutation in LARS as a novel cause of infantile hepatopathy, Mol. Genet. Metab. 106 (2012) 351-358, https://doi.org/10.1016/j.ymgme.2012.04.017.

[31] J.P. Casey, S. Slattery, M. Cotter, A.A. Monavari, I. Knerr, J. Hughes, E.P. Treacy, D. Devaney, M. McDermott, E. Laffan, D. Wong, S.A. Lynch, B. Bourke, E. Crushell, Clinical and genetic characterisation of infantile liver failure syndrome type 1, due to recessive mutations in LARS, J. Inherit. Metab. Dis. 38 (2015) 1085-1092, https://doi.org/10.1007/s10545-015-9849-1.

[32] E. van Meel, D.J. Wegner, P. Cliften, M.C. Willing, F.V. White, S. Kornfeld, F.S. Cole, Rare recessive loss-of-function methionyl-tRNA synthetase mutations presenting as a multi-organ phenotype, BMC Med. Genet. 14 (2013) 106, , https://doi.org/10. 1186/1471-2350-14-106.

[33] R. Kopajtich, K. Murayama, A.R. Janecke, T.B. Haack, M. Breuer, A.S. Knisely, I. Harting, T. Ohashi, Y. Okazaki, D. Watanabe, Y. Tokuzawa, U. Kotzaeridou, S. Kölker, S. Sauer, M. Carl, S. Straub, A. Entenmann, E. Gizewski, R.G. Feichtinger, J.A. Mayr, K. Lackner, T.M. Strom, T. Meitinger, T. Müller, A. Ohtake, G.F. Hoffmann, H. Prokisch, C. Staufner, Biallelic IARS mutations cause growth retardation with prenatal onset, intellectual disability, muscular hypotonia, and infantile hepatopathy, Am. J. Hum. Genet. 99 (2016) 414-422, https://doi.org/10 1016/j.ajhg.2016.05.027.

[34] P. Gissen, C.A. Johnson, N.V. Morgan, J.M. Stapelbroek, T. Forshew, W.N. Cooper, P.J. McKiernan, L.W.J. Klomp, A.A.M. Morris, J.E. Wraith, P. McClean, S.A. Lynch, R.J. Thompson, B. Lo, O.W. Quarrell, M. Di Rocco, R.C. Trembath, H. Mandel, S. Wali, F.E. Karet, A.S. Knisely, R.H.J. Houwen, D.A. Kelly, E.R. Maher, Mutations in VPS33B, encoding a regulator of SNARE-dependent membrane fusion, cause arthrogryposis-renal dysfunction-cholestasis (ARC) syndrome, Nat. Genet. 36 (2004) 400-404, https://doi.org/10.1038/ng1325.

[35] A.R. Cullinane, A. Straatman-Iwanowska, A. Zaucker, Y. Wakabayashi, C.K. Bruce, G. Luo, F. Rahman, F. Gürakan, E. Utine, T.B. Ozkan, J. Denecke, J. Vukovic, M. Di Rocco, H. Mandel, H. Cangul, R.P. Matthews, S.G. Thomas, J.Z. Rappoport, I.M. Arias, H. Wolburg, A.S. Knisely, D.A. Kelly, F. Müller, E.R. Maher, P. Gissen, Mutations in VIPAR cause an arthrogryposis, renal dysfunction and cholestasis syndrome phenotype with defects in epithelial polarization, Nat. Genet. 42 (2010) 303-312, https://doi.org/10.1038/ng.538.

[36] A. El-Gharbawy, S. Ranganathan, L. Ghaloul-Gonzalez, J. Sebastian, K. Sheffler, V. Venkat, S. Doborowski, A. Goldstein, J. Vockley, Management of two patients with infantile liver failure syndrome type I due to LARS mutations: an under recognized reversible hepatopathy (P-462), J. Inherit. Metab. Dis. 41 (2018) S218, https://doi.org/10.1007/s10545-018-0232-x.

[37] A.G. Feldman, P.F. Whitington, Neonatal hemochromatosis, J. Clin. Exp. Hepatol. 3 (2013) 313-320, https://doi.org/10.1016/j.jceh.2013.10.004.

[38] E. Pronicka, A. Węglewska-Jurkiewicz, J. Taybert, M. Pronicki, T. SzymańskaDębińska, A. Karkucińska-Więckowska, J. Jakóbkiewicz-Banecka, P. Kowalski, D. Piekutowska-Abramczuk, M. Pajdowska, P. Socha, J. Sykut-Cegielska, G. Węgrzyn, Post mortem identification of deoxyguanosine kinase (DGUOK) gene mutations combined with impaired glucose homeostasis and iron overload features in four infants with severe progressive liver failure, J. Appl. Genet. 52 (2011) 61-66, https://doi.org/10.1007/s13353-010-0008-y.

[39] N.A. Hanchard, O.A. Shchelochkov, A. Roy, J. Wiszniewska, J. Wang, E.J. Popek, S. Karpen, L.-J.C. Wong, F. Scaglia, Deoxyguanosine kinase deficiency presenting as neonatal hemochromatosis, Mol. Genet. Metab. 103 (2011) 262-267, https://doi. org/10.1016/j.ymgme.2011.03.006.

[40] S. Nobre, M. Grazina, F. Silva, C. Pinto, I. Gonçalves, L. Diogo, Neonatal liver failure due to deoxyguanosine kinase deficiency, BMJ Case Rep. 2012 (2012), https://doi. org/10.1136/bcr.12.2011.5317.

[41] S. Heissat, S. Collardeau-Frachon, J. Baruteau, E. Dubruc, R. Bouvier, M. Fabre, M.P. Cordier, P. Broué, V. Guigonis, D. Debray, Neonatal hemochromatosis: diagnostic work-up based on a series of 56 cases of fetal death and neonatal liver failure, J. Pediatr. 166 (2015) 66-73, https://doi.org/10.1016/j.jpeds.2014.09.030.

[42] L. Sniderman King, C. Trahms, C.R. Scott, I. Tyrosinemia Type, M.P. Adam, H.H. Ardinger, R.A. Pagon, S.E. Wallace, L.J. Bean, K. Stephens, A. Amemiya (Eds.), GeneReviews ${ }^{\circledR}$, University of Washington, Seattle, Seattle (WA), 1993, http://www. 
ncbi.nlm.nih.gov/books/NBK1515/ (accessed December 7, 2018).

[43] J.D. Korman, I. Volenberg, J. Balko, J. Webster, F.V. Schiodt, R.H. Squires, R.J. Fontana, W.M. Lee, M.L. Schilsky, Pediatric and Adult Acute Liver Failure Study Groups, Screening for Wilson disease in acute liver failure: a comparison of currently available diagnostic tests, Hepatol. Baltim. Md. 48 (2008) 1167-1174, https://doi.org/10.1002/hep.22446.

[44] D.H. Berman, R.I. Leventhal, J.S. Gavaler, E.M. Cadoff, D.H. Van Thiel, Clinical differentiation of fulminant Wilsonian hepatitis from other causes of hepatic failure, Gastroenterology. 100 (1991) 1129-1134.

[45] P. Hargreaves, S. Rahman, P. Guthrie, J.W. Taanman, J.V. Leonard, J.M. Land, S.J.R. Heales, Diagnostic value of succinate ubiquinone reductase activity in the identification of patients with mitochondrial DNA depletion, J. Inherit. Metab. Dis. 25 (2002) 7-16.

[46] P.T. Clayton, Disorders of bile acid synthesis, J. Inherit. Metab. Dis. 34 (2011) 593-604, https://doi.org/10.1007/s10545-010-9259-3.

[47] J.M. Stapelbroek, K.J. van Erpecum, L.W.J. Klomp, R.H.J. Houwen, Liver disease associated with canalicular transport defects: current and future therapies, J. Hepatol. 52 (2010) 258-271, https://doi.org/10.1016/j.jhep.2009.11.012.

[48] E. Gonzales, S.A. Taylor, A. Davit-Spraul, A. Thébaut, N. Thomassin, C. Guettier, P.F. Whitington, E. Jacquemin, MYO5B mutations cause cholestasis with normal serum gamma-glutamyl transferase activity in children without microvillous inclusion disease, Hepatol. Baltim. Md. 65 (2017) 164-173, https://doi.org/10.1002/ hep.28779.

[49] Y.-L. Qiu, J.-Y. Gong, J.-Y. Feng, R.-X. Wang, J. Han, T. Liu, Y. Lu, L.-T. Li, M.H. Zhang, J.A. Sheps, N.-L. Wang, Y.-Y. Yan, J.-Q. Li, L. Chen, C.H. Borchers, B. Sipos, A.S. Knisely, V. Ling, Q.-H. Xing, J.-S. Wang, Defects in myosin VB are associated with a spectrum of previously undiagnosed low $\gamma$-glutamyltransferase cholestasis, Hepatol. Baltim. Md. 65 (2017) 1655-1669, https://doi.org/10.1002/ hep. 29020 .

[50] M. Girard, F. Lacaille, V. Verkarre, R. Mategot, G. Feldmann, A. Grodet, F. Sauvat, S. Irtan, A. Davit-Spraul, E. Jacquemin, F. Ruemmele, D. Rainteau, O. Goulet, V. Colomb, C. Chardot, A. Henrion-Caude, D. Debray, MYO5B and bile salt export pump contribute to cholestatic liver disorder in microvillous inclusion disease, Hepatol. Baltim. Md. 60 (2014) 301-310, https://doi.org/10.1002/hep.26974.

[51] K. Oishi, R. Arnon, M.P. Wasserstein, G.A. Diaz, Liver transplantation for pediatric inherited metabolic disorders: considerations for indications, complications, and perioperative management, Pediatr. Transplant. 20 (2016) 756-769, https://doi. org/10.1111/petr.12741.

[52] S. Parikh, A. Karaa, A. Goldstein, Y.S. Ng, G. Gorman, A. Feigenbaum, J. Christodoulou, R. Haas, M. Tarnopolsky, B.K. Cohen, D. Dimmock, T. Feyma, M.K. Koenig, H. Mundy, D. Niyazov, R.P. Saneto, M.S. Wainwright, C. Wusthoff, R. McFarland, F. Scaglia, Solid organ transplantation in primary mitochondrial disease: proceed with caution, Mol. Genet. Metab. 118 (2016) 178-184, https://doi. org/10.1016/j.ymgme.2016.04.009.

[53] G. Mazariegos, B. Shneider, B. Burton, I.J. Fox, N. Hadzic, P. Kishnani, D.H. Morton, S. McIntire, R.J. Sokol, M. Summar, D. White, V. Chavanon, J. Vockley, Liver transplantation for pediatric metabolic disease, Mol. Genet. Metab. 111 (2014) 418-427, https://doi.org/10.1016/j.ymgme.2014.01.006.

[54] A. Dhawan, R.M. Taylor, P. Cheeseman, P. De Silva, L. Katsiyiannakis, G. MieliVergani, Wilson's disease in children: 37-year experience and revised King's score for liver transplantation, Liver Transpl. Off. Publ. Am. Assoc. Study Liver Dis. Int. Liver Transplant. Soc. 11 (2005) 441-448, https://doi.org/10.1002/lt.20352. 